\title{
Sub-inner limiting membrane hemorrhage following a laser show
}

\section{Hemorragia submembrana limitante interna secundaria a láser de espectáculos}

\author{
Claudia K. Martínez-Hernández*, Jorge A. Sánchez-Ramos, Adriana Saucedo-Castillo, and \\ J. Abel Ramírez-Estudillo \\ Retina and Vitreous Department, Fundación Hospital Nuestra Señora de la Luz, Institución de Asistencia Privada (IAP), Mexico City, Mexico
}

\begin{abstract}
This is the case of a 26-year-old man that presented a visual acuity decrease after unintentionally looking at a light projected in a laser show. On examination, a premacular hemorrhage was observed in the left eye. Optical coherence tomography demonstrated the presence of a sub-inner limiting membrane hemorrhage. A pars plana vitrectomy was performed with internal limiting membrane peeling, followed by rapid visual acuity improvement.
\end{abstract}

Key words: Ocular laser injury. Macular hemorrhage. Sub-internal limiting membrane hemorrhage. Laser. Retina.

\section{Resumen}

Presentación de un caso clínico de un paciente de sexo masculino de 26 años, que acude por baja visual, tras ver accidentalmente una luz proyectada por un láser de espectáculos, y que presenta una hemorragia prerretiniana en el ojo izquierdo. La tomografía de coherencia óptica mostró la presencia de una hemorragia sublimitante interna. Se le realizó una vitrectomía pars plana con pelado de la limitante interna, y se produjo una rápida mejoría de la agudeza visual.

Palabras clave: Daño ocular por láser. Hemorragia macular. Hemorragia sub-MLI. Láser. Retina.

\section{Introduction}

The development of the laser allows the availability of this technology in multiple devices used in our daily lives and in more specific applications. Most laser-associated injuries are usually related to accidents with low-power laser pointers $(<5 \mathrm{~mW})^{1}$. Different types of retinal lesions have been described, involving the fovea or juxtafoveal areas such as ring-shaped hypopigmented lesions, window defects due to alterations of the retinal pigment epithelium, retinal scars, intra and subretinal hemorrhage, vitreous and premacular hemorrhage (mainly due to pulsed dye laser), and macular hole ${ }^{2}$. It is important to highlight the formation of premacular hemorrhages due to serious eye damage it can

Correspondence:

*Claudia K. Martínez-Hernández

Ezequiel Montes, 135

Col. Tabacalera, Del. Cuauhtémoc

Date of reception: 11-05-2019

Date of acceptance: 05-09-2019

DOI: 10.24875/RMOE.M20000147
Available online: 11-01-2021 Rev Mex Oftalmol (Eng). 2021;95(1):37-40 www.rmo.com.mx 
inflict. Different forms of treatment have been described, ranging from observation to vitrectomy.

\section{Clinical case}

A 26-year-old male patient, resident of Mexico City, whose job is organizing lighting and sound shows at social events. He denied family, personal pathological and non-pathological history, and only indicates as ocular history of the use of eyeglasses since adolescence. He refers to the accidental sight of light projected by a laser console for a few seconds while he was making a purchase of equipment for the lighting show, with subsequent sudden and non-painful visual loss of the left eye of 1 day of evolution. The patient does not remember the color of the laser light.

Physical examination revealed a visual acuity in the right eye of 20/200, with a visual capacity of $20 / 20$, and in the left eye of $20 / 800$, with a visual capacity of $20 / 400$; and a refraction in the right eye of $-3.00=-1.25$ $\times 170^{\circ}$ and in the left eye of $-2.75=-1.25 \times 180^{\circ}$. The anterior segment of both eyes was normal, with preserved pupillary reflexes and normal intraocular pressure. The right eye fundus was normal, while the left eye showed a macular pre-retinal hemorrhage of approximately 2 disc diameters, with an excavation of $45 \%$ of the optic nerve (Fig. 1). Fluorescein angiography showed hypofluorescence due to blockage in the left eye at the level of the hemorrhage (Fig. 2). General laboratory tests were performed, which included full blood count and chemistry panel, clotting times, and viral profile, which were all normal. A spectral-domain optical coherence tomography showed a dome-shaped lesion corresponding to a subhyaloid hemorrhage, divided by a median reflectivity line that corresponds to the internal limiting membrane, which separates the subhyaloid hemorrhage from the sub-internal limiting hemorrhage (Fig. 3). We performed a 23-gauge pars plana vitrectomy with brilliant blue-assisted internal limiting peeling. The patient had a favorable evolution, with a visual capacity in both eyes of 20/20 at 6 months of follow-up (Fig. 4).

\section{Discussion}

The first publications regarding laser injuries are associated with accidental exposure to laser in the military or laboratories. In 2004, the worldwide frequency of laser injuries was estimated to be $<15$ cases $^{3}$. However, due to the increased availability of commercial lasers, the frequency of these injuries has increased.

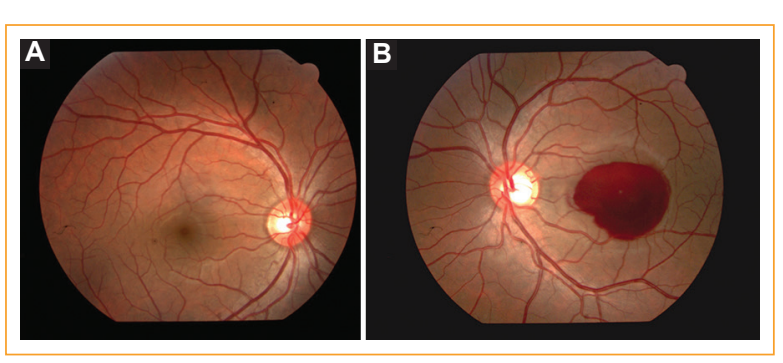

Figure 1. The right eye normal fundus photograph (A) and the left eye fundus photograph with a premacular hemorrhage of approximately 2 disc diameters, with an approximate excavation of $45 \%$ of the optic nerve (B).
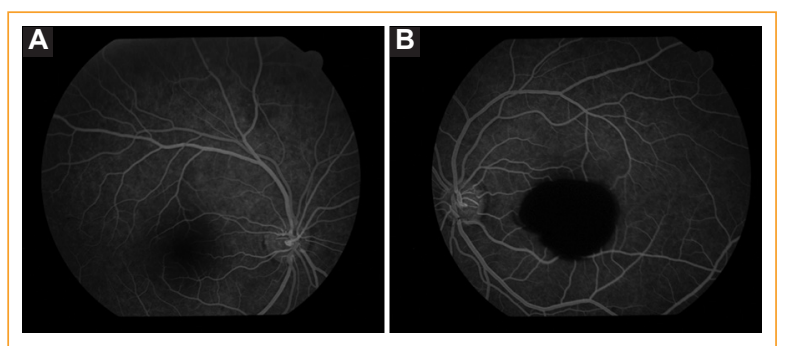

Figure 2. Fluorescein angiography of the right eye without vascular alterations (A) and of the left eye with hypofluorescence due to blockage at the level of the hemorrhage (B).

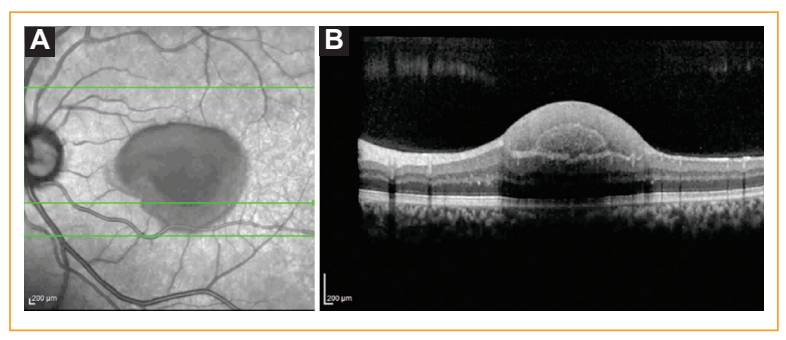

Figure 3. Spectral-domain optical coherence tomography of the left eye, showing a dome-shaped lesion that corresponds to a subhyaloid hemorrhage, divided by a medium reflectivity line that corresponds to the internal limiting membrane and that separates the subhyaloid hemorrhage from the sub-internal limiting hemorrhage.

Although laser injuries can be bilateral, most of them are unilateral because they occur at short distances ${ }^{4}$, accidentally or also self-inflicted with laser pointers, whose output power is usually $1-5 \mathrm{~mW}$. More serious injuries have been associated with Q-switched lasers ${ }^{4-6}$. Blink reflex and aversion response limit exposure time to $0.15-0.25 \mathrm{~s}^{2}$. With short wavelengths and prolonged exposure, tissue damage 


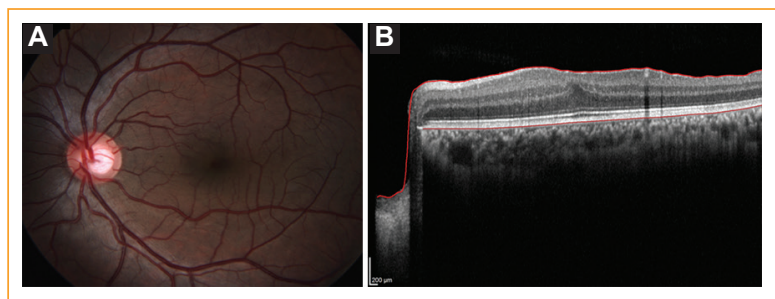

Figure 4. Fundus photography $\mathbf{A}$ : and spectral-domain optical coherence tomography B: of the left eye 6 months after treatment, where a decrease in foveal depression and irregularity of the internal layers in the temporal region are observed, without pre-retinal hemorrhage.

has been shown to be greater, even with a low-power laser-9.

The retina is the ocular tissue most sensitive to laser injury due to the focus of light and irradiation that is amplified by 5-6 orders of magnitude. Chromatic aberration and mild myopia produce an anterior focus for the laser that also increases the susceptibility of the retina ${ }^{10}$.

The macula is especially susceptible, due to the greater absorption of laser energy due to the presence of pigments such as melanin, xanthophyllic pigment, and hemoglobin ${ }^{10}$.

The mechanisms through which the laser exerts its action are the photochemical effect, photoablation, photocoagulation, and optical photodisruption; both photocoagulation and optical photodisruption are the ones that disrupt retinal vessels and produce self-limited bleeding ${ }^{11}$.

In Mexico, there are no organizations that regulate the manufacture of commercial lasers, which has produced an increase in the occurrence of cases ${ }^{12}$. Associations such as the American National Standard for Safe Use of Lasers classify them based on their safety as potentially harmful to the eye when the output power is $>5 \mathrm{~mW}$, and capable of producing serious eye damage when the output power is more than $500 \mathrm{~mW}$. They also establish the maximum permissible exposure of $25.4 \mathrm{~W} / \mathrm{m}^{2}$ for a period of $250 \mathrm{~ms}$, equivalent to $1 \mathrm{~mW}$ in a pupil diameter of $7 \mathrm{~mm}^{13,14}$.

Commercially available lighting show lasers are typically $800 \mathrm{~mW}-3 \mathrm{~W}$ in power, typically have blanking scanners or other scanning systems for complex beam and graphic projections ${ }^{11}$. In this case, the patient did not know the color and power of the laser; however, due to the disease mechanism and the type of laser consoles used in shows, it is considered that it could have been a class 3B laser, commonly used for shows; a green laser with a $50 \mathrm{~mW}$ power (with a wavelength of around $532 \mathrm{~nm}$ ) or a red laser with a $120 \mathrm{~mW}$ power (with a wavelength of around $650 \mathrm{~nm}$ ).

The goal of treatment is to eliminate the hemorrhage $^{15}$ and prevent complications, such as membrane formation and proliferative vitreoretinopathy ${ }^{16}$, as well as destructive toxic effects to the tissue from prolonged exposure. It should be remembered that the left sub-internal limiting membrane hemorrhage tends to remain longer than the subhyaloid hemorrhage ${ }^{17}$.

Different treatment options have been used, such as observation $2,11,18$; however, it requires close monitoring and, the greater the hemorrhage, the slower the reabsorption is, and not all patients regain their visual capacity ${ }^{19}$. The YAG laser allows the drainage of blood into the vitreous cavity and is reabsorbed in an average of 6 weeks. It is recommended for hemorrhages $>3$ disc diameters, but its association with a macular hole has limited its use ${ }^{2,20}$. Vitrectomy with or without internal limiting membrane peeling has shown to induce a significant and immediate visual improvement and can prevent complications such as amblyopia or myopia in children, as well as those derived from the lack of an adequate evaluation of the deeper layers $^{2,12,20}$. Other techniques such as hemolysis and pneumodisplacement have been described ${ }^{15}$; however, they require the use of drugs that are difficult to handle and are mainly described for the treatment of subretinal hemorrhages.

\section{Conclusion}

Lasers can cause serious eye damage. The increase in cases, especially in our environment, reiterates the importance of regulating the use and commercialization of lasers not only the pointers but also those used in our daily life. Vitrectomy is an effective technique for the resolution of premacular hemorrhages with few complications.

\section{Funding}

The authors declare that no funding was obtained for this publication.

\section{Conflicts of interest}

The authors declare no conflicts of interest. 


\section{Ethical disclosures}

Protection of human and animal subjects. The authors declare that no experiments were performed on humans or animals for this study.

Confidentiality of data. The authors declare that they have followed the protocols of their work center on the publication of patient data.

Right to privacy and informed consent. The authors have obtained the written informed consent of the patients or subjects mentioned in the article. The corresponding author is in possession of this document. This article does not contain personal data.

\section{References}

1. Wyrsch S, Baenninger PB, Schmid MK. Retinal injuries from a handheld laser pointer. N Engl J Med. 2010;363(11):1089-91.

2. Alsulaiman SM, Alrushood AA, Almasaud J, Alzaaidi S, Alzahrani $Y$, Arevalo JF, et al; King Khaled Eye Specialist Hospital Collaborative Retina Study Group. High-power handheld blue laser-induced maculopathy: the results of the King Khaled Eye Specialist Hospital Collaborative Retina Study Group. Ophthalmology. 2014121(2):566-72.e1.

3. Mainster MA, Stuck BE, Brown J Jr. Assessment of alleged retinal laser injuries. Arch Ophthalmol. 2004;122: 1210-7.

4. Turaka K, Bryan JS, Gordon AJ, Reddy R, Kwong HM Jr, Sell CH. Laser pointer induced macular damage: case report and mini review. Int Ophthalmol. 2012;32(3):293-7.

5. Fujinami K, Yokoi T, Hiraoka M, Nishina S, Azuma N. Choroidal neovascularization in a child following laser pointer-induced macular injury. Jpn J Ophthalmol. 2010;54(6):631-3

6. Wyrsch S, Baenninger PB, Schmid MK. Retinal injuries from a handheld laser pointer. N Engl J Med. 2010;363(11):1089-91.
7. Denton ML, Foltz MS, Schuster KJ, Noojin GD, Estlack LE, Thomas RJ. In vitro model that approximates retinal damage threshold trends. J Biomed Opt. 2008;13(5):054014.

8. Katoh N, Peyman GA. Effects of laser wavelengths on experimental retinal detachments and retinal vessels. Jpn J Ophthalmol. 1988;32(2):196-210.

9. Ham WT Jr, Ruffolo JJ Jr, Mueller HA, Clarke AM, Moon ME. Histologic analysis of photochemical lesions produced in rhesus retina by short-wave-length light. Invest Ophthalmol Vis Sci. 1978;17:1029-35.

10. Yiu G, Itty S, Toth CA. Ocular safety of recreational lasers. JAMA Ophthalmol. 2014;132(3):245-6.

11. Shneck M, Levy J, Klemperer I, Lifshitz T. Retinal laser injury during a laser show. Retin Cases Brief Rep. 2007;1(3):178-81.

12. Perez-Montaño CR, Palomares-Ordoñez JL, Ramirez-Estudillo A, Sanchez-Ramos J, González-Saldivar G. Sub-hyaloid and sub-internal limiting membrane macular hemorrhage after laser exposure at music festival: a case report. Doc Ophthalmol. 2019;138(1):71-6.

13. American National Standard for Safe Use of Lasers. Orlando, FL: Laser Institute of America. ANSI Z136.1e2007. Disponible en: http://www.lia.org/ PDF/Z136 1 s.pdf.

14. FDA safety notification: risk of eye and skin injuries from high-powered, hand-held lasers used for pointing or entertainment, US Food and Drug Administration. Disponible en: https://wayback.archive-it. org/7993/20170111092815/http://www.fda.gov/MedicalDevices/Safety/ AlertsandNotices/ucm237129.htm.

15. Mennel S. Subhyaloidal and macular haemorrhage: localisation and treatment strategies. Br J Ophthalmol. 2007;91(7):850-2.

16. Velikay M, Datlinger P, Stolba U, Wedrich A, Binder S, Hausmann N. Retinal detachment with severe proliferative vitreoretinopathy in Terson syndrome. Ophthalmology. 1994;101(1):35-7.

17. Ulbig MW, Mangouritsas G, Rothbacher HH, Hamilton AM, McHugh JD. Long-term results after drainage of premacular subhyaloid hemorrhage into the vitreous with a pulsed Nd:YAG laser. Arch Ophthalmol. 1998; $116(11): 1465-9$

18. Yeo DC, Osei-Bempong C, Shirodkar A, Williams GS. Foveal haemorrhage from makeshift 'Lightsaber': funduscopy and optical coherence tomography findings. BMJ Case Rep. 2016;2016: bcr2016214711.

19. De Maeyer K, Van Ginderdeuren R, Postelmans L, Stalmans P, Van Calster J. Sub-inner limiting membrane haemorrhage: causes and treatment with vitrectomy. Br J Ophthalmol. 2007;91(7):869-72.

20. Durukan AH, Kerimoglu H, Erdurman C, Demirel A, Karagul S. Long-term results of $\mathrm{Nd}$ : YAG laser treatment for premacular subhyaloid haemorrhage owing to Valsalva retinopathy. Eye (Lond). 2008;22:214-8. 